UCRL-ID-125914

\title{
Predictions of acoustic signals from explosions above and below the ocean surface: source region calculations
}

\author{
Douglas B. Clarke \\ Andrew Piacsek \\ John W. White \\ 8 \\ This paper is submitted as \\ CTBT Ocean Monitoring Research Deliverable No. H2.2.1
}

December 1996

This is an informal report intended primarily for internal or limited external distribution. The opinions and conclusions stated are those of the author and may or may not be those of the Laboratory.

Work performed under the auspices of the U.S. Department of Energy by the Lawrence Livermore National Laboratory under Contract W-7405-Eng-48. 


\section{DISCLAIMER}

This document was prepared as an account of work sponsored by an agency of the United States Government. Neither the United States Government nor the University of California nor any of their employees, makes any warranty, express or implied, or assumes any legal liability or responsibility for the accuracy, completeness, or usefulness of any information, apparatus, product, or process disclosed, or represents that its use would not infringe privately owned rights. Reference herein to any specific commercial product, process, or service by trade name, trademark, manufacturer, or otherwise, does not necessarily constitute or imply its endorsement, recommendation, or favoring by the United States Government or the University of California. The views and opinions of authors expressed herein do not necessarily state or reflect those of the United States Government or the University of California, and shall not be used for advertising or product endorsement purposes.

This report has been reproduced directly from the best available copy.

Available to DOE and DOE contractors from the Office of Scientific and Technical Information

P.O. Box 62, Oak Ridge, TN 37831

Prices available from (615) 576-8401, FTS 626-8401

Available to the public from the

National Technical Information Service

U.S. Department of Commerce

5285 Port Royal Rd.,

Springfield, VA 22161 


\title{
Predictions of acoustic signals from explosions above and below the ocean surface: Source region calculations
}

\author{
Douglas B. Clarke, Andrew Piacsek, and John W. White
}

\begin{abstract}
In support of the Comprehensive Test Ban, research is underway on the long range propagation of signals from nuclear explosions in the deep underwater sound (SOFAR) channel. This first phase of our work at LLNL on signals in the source regions considered explosions in or above the deep $(5000 \mathrm{~m})$ ocean. We studied the variation of wave properties and source region energy coupling as a function of height or depth of burst. Initial calculations on CALE, a two-dimensional hydrodynamics code developed at LLNL by Robert Tipton, were linked at a few hundred milliseconds to a version of NRL's weak shock code, NPE, which solves the nonlinear progressive wave equation. The wave propagation simulation was performed down to $5000 \mathrm{~m}$ depth and out to $10,000 \mathrm{~m}$ range. We have developed a procedure to convert the acoustic signals at $10 \mathrm{~km}$ range into "starter fields" for calculations on a linear acoustics code which will extend the propagation to ocean basin distances.
\end{abstract}

Recently we have completed calculations to evaluate environmental effects (shallow water, bottom interactions) on signal propagation. We compared results at $25 \mathrm{~km}$ range from three calculations of the same 1 kiloton burst ( $50 \mathrm{~m}$ height-of-burst) in three different environments, namely, deep water, shallow water, and a case with shallow water sloping to deep water. Several results from this last "sloping bottom" case will be discussed below. In this shallow water study, we found that propagation through shallow water complicates and attenuates the signal; the changes made to the signal may impact detection and discrimination for bursts in some locations.

\section{INTRODUCTION AND SUMMARY}

Our calculations in the source region for nuclear explosions above and below the ocean surface are part of a continuing effort at Lawrence Livermore National Laboratory to understand how the source region phenomena contribute to the signals which would be detected at ocean basin distances from such explosions. In support of the Comprehensive Test Ban, we have completed calculations and analysis for one kiloton explosions in a variety of environments. The overall goal of this work is to establish the long-range signature of large explosions to assist in detection and discrimination wherever the explosion may be, including underwater explosions or explosions in the low atmosphere.

The purpose of this document is to report the main results of our source region calculations, including results on energy coupling to the ocean by explosions above and below the ocean surface. We also report more recent work on the effects of the near source environment (e.g. shallow water, bottom materials) on signal characteristics.

The initial high temperature, high pressure non-linear phase of our calculations was completed using the LLNL hydrodynamics code CALE (Tipton, 1995). After a time, typically a few hundred milliseconds, the pressures had dropped to less than 100 atmospheres $\left(10^{7} \mathrm{~Pa}\right)$. At this stage the motion was "linked" (transferred) to the weak- 
shock propagation code, NPE (Nonlinear Progressive wave Equation), developed by Ed McDonald and others at the Naval Research Laboratory4-6. With NPE, the calculations can be extended to distances of tens of kilometers (or times of tens of seconds), at which point the near-source-region phase has been completed.

Earlier we completed a set of ten calculations of one-kiloton explosions in or above the deep ocean. One advantage of beginning our simulations with the deep (5000 m) ocean was that this choice was the simplest case, since the depth allowed us to make the approximation that interaction with the bottom was a minor effect compared to the explosion and the development of the main shock wave. With these Deep Ocean calculations we have made predictions for the amount of energy coupled by an explosion within $1000 \mathrm{~m}$ of the ocean surface. With these ten calculations we varied the burst location from $1000 \mathrm{~m}$ below the surface ( = fully coupled) to $1000 \mathrm{~m}$ above the surface. We compared the total energy in the wave in the NPE grid at approximately $10,000 \mathrm{~m}$ range. This distance was chosen because it was twice the (simulated) ocean depth. It was expected that when the signal reached this range, the energy coupling and evolution into a deep ocean signal would be complete. The results formed the so-called coupling curve for bursts in or above the deep ocean and show that the coupling efficiency declines precipitously as the burst point in raised through the ocean surface. However, we predict that explosions above the ocean surface will produce observable hydroacoustic signals, and these signals will be unusual for their short duration and relatively low frequency content. Theresults from the ten calculations in the Deep Ocean study are being made available to other contractors in the form of "starting fields" for studies of long range propagation in ocean environments. Some results from this work were reported the first two references (Clarke, White and Harris, 1995; and Clarke, 1996).

More recently we have completed a so-called shallow water study in an effort to understand the effects of the water environment (shallow or deep) and bottom effects -propagation in and attenuation by the mud or rock. We compared the results from three calculations of a one kiloton source burst $50 \mathrm{~m}$ above the surface. Each calculation had a different configuration (deep, shallow or sloping bottom). Unlike the Deep Ocean study, some effects of an ocean bottom were included. Working with Ed McDonald we made improvements to NPE to account for attenuation in the bottom. NPE is nearly acoustic, and it is limited to modeling bottom materials such as rock, sand or mud as fluids (no strength, no shear waves). These mud-like layers may however have a higher sound speed than water. In this study all three calculations had two layers of mud-like materials forming the bottom.

The NPE calculations were stopped after propagation for 17 seconds, equivalent to about 25 kilometers, a distance still much smaller than ocean basin distances. Comparing the signals in the three cases, we found that propagation through shallow water complicates and attenuates the signal. The case with the flat bottom (uniform $200 \mathrm{~m}$ depth) showed significant loss of energy, a peak pressure about 10 times lower than the other cases, signal dispersion and a shift toward low frequencies in the spectral shape. Both shallow water cases have more structure in the waves than the deep case. The changes made to the signal by propagation through shallow water may impact detection and discrimination for bursts in some locations.

Results from the shallow water study form a first step in understanding properties of explosion signals in the near-source region in/above a variety of environments. One could also expect that data could be created for starter fields for long range propagation. 


\section{REFERENCES ...}

1. Clarke, D. B., J. W. White and D. B. Harris, "Hydroacoustic Coupling Calculations for Underwater and Near Surface Explosions," UCRL-ID-122098, Sept. 1995, (U)

2. Clarke, Douglas B., "Pressure Time Histories Derived From Hydroacoustic Coupling Calculations: The Transition to Long Range Linear Acoustics," UCRL-ID-122595, December 1996, (U).

3. Tipton, Robert, "CALE Users Manual, Version 950101," LLNL Internal Report, March 1995. For further information on CALE, contact D. B. Clarke, LLNL, PO Box 808, L-200, Livermore CA 94551. - (510) 422-6593 Email: clarke1@llnl.gov.

4. McDonald, B. E. and W. A. Kuperman, "Time-Domain Solution of the Parabolic Equation Including Non-Linearity," Comp. and Maths. with Appls., Vol. 11, pp. 843-851, Pergamon Press Ltd, UK (1985)

5. McDonald, B. E. and W. A. Kuperman, "Time Domain formulation for pulse propagation including nonlinear behavior at a caustic," J. Acoustic Soc. Am., Vol. 81, pp. 1406-1417 (1987)

6. Ambrosiano, J. J., D. R. Plante, B. E. McDonald and W. A. Kuperman, "Nonlinear Propagation in an Ocean Acoustic Waveguide," J. Acoustic Soc. Am., Vol. 87 (4), p. 1473-1482 (1990). 


\title{
Predictions of acoustic signals from explosions above and below the ocean surface: Source region calculations
}

\author{
Douglas B. Clarke, Andrew Piacsek, and John W. White \\ Lawrence Livermore National Laboratory
}

November 19, 1996

Work performed under the auspices of the U. S. Department of Energy under contract number W-7405-ENG-48. 


\section{Source}

Goals: Establish long-range signature of explosions in a variety of environments, assist detection and discrimination

- underwater explosions

- explosions in the low atmosphere

- deep and shallow water

Progress to date:

- coupling curve for explosions in the low-atmosphere

- starter fields for long-range acoustic propagation

Results:

- explosions above the ocean surface produce observable hydroacoustic signals

short duration

low frequency

- shallow water complicates and attenuates the signal, which may impact detection and discrimination 
How does the signal from a nuclear explosion at sea affected by burst height and near-source environment?

How does energy coupled to water decrease"as burst location changes from, deep to at the surface to high above the surface?

- Energy Coupling study of bursts in or above deep ocean water

- Simplest case

- Ignore near-source bottom effects

- Provides start fields for initial studies of long-range propagation

How would the signal from a burst over shallow water be different?

What is the effect of coupling to and/or attenuation in bottom materials?

- Shallow water study compares results from three cases:

- Deep water

- Shallow flat bottom

- Shallow sloping bottom

- Study restricted by NPE models for bottom materials

- Mud-like fluids with higher sound speeds but no shear waves

- Eventual goal is to provide a catalog of starter fields for a variety of Burst locations and near-source environments 
- Mechanical radiation - hydroacoustic, seismic, infrasound

- Detection is simple, straight-forward, cheap and reliable

- Basic to the explosion so cannot be hidden or modified easily

- Useful for both detection and discrimination

- Other types of radiated signals are detected on a less cost-effective basis 
- Compare wave energy, peak pressure, or frequency content as burst location is changed

Assume

- Deep ocean (5000 m)

- One kiloton source, modeled as ball of gaseous iron

- Main underwater shock followed to $10 \mathrm{~km}$ range

- Burst location varied from $1000 \mathrm{~m}$ below surface (fully coupled)

to $1000 \mathrm{~m}$ above surface

- Link from CALE hydrodynamics code to NPE performed when peak pressure is less than 100 bars $\left(10^{7} \mathrm{~Pa}\right)$

- Range is then less than $500 \mathrm{~m}$ for underwater bursts 
- CALE: Arbitrary Lagrangian - Eulerian hydrodynamics code, written in $\underline{\mathrm{C}}$ language at LLNL by Bob Tipton

- Solves equations for conservation of mass, momentum and energy

- Equations of state and constitutive models (strength, failure)

- Full scale hydrodynamics treatment needed in first phase

- High initial pressures

- Strong shock conditions

- Blast wave in air (in some cases)

- For buried bursts

- Impact of shock wave on water surface

- Cratering motion in water, or bubble

- Pressures quickly drop below one kilobar (100 MPa) 
NPE: Non-Linear Progressive-wave Equation code

- Code obtained from Ed McDonald, NRL *

- Physics in LLNL version the same as NRL's

- Some differences in graphics, $1 / 0$, production setup

- Runs on Silicon Graphics workstations and Challenge L

\section{References:}

McDonald, B. E. and W. A. Kuperman, "Time-Domain Solution of the Parabolic Equation Including Non-Linearity," Comp. and Maths. with Appls., Vol. 11, 843-851, Pergamon Press Ltd, UK (1985)

B. E. McDonald and W. A. Kuperman, "Time Domain formulation for pulse propagation including nonlinear behavior at a caustic," J. Acoustic Soc. Am., Vol. 81, p. 1406-1417 (1987)

Ambrosiano, J. J., D. R. Plante, B. E. McDonald and W. A. Kuperman, "Nonlinear Propagation in an Ocean Acoustic Waveguide," J. Acoustic Soc. Am., Vol. 87 (4), p. 1473-1482 (1990) 
NIli: Conlexl.

- 'line domain

a. Simall angle propagalion

- Equations cast in pulse capluring frame

- Iowesl order nonlinearily relained

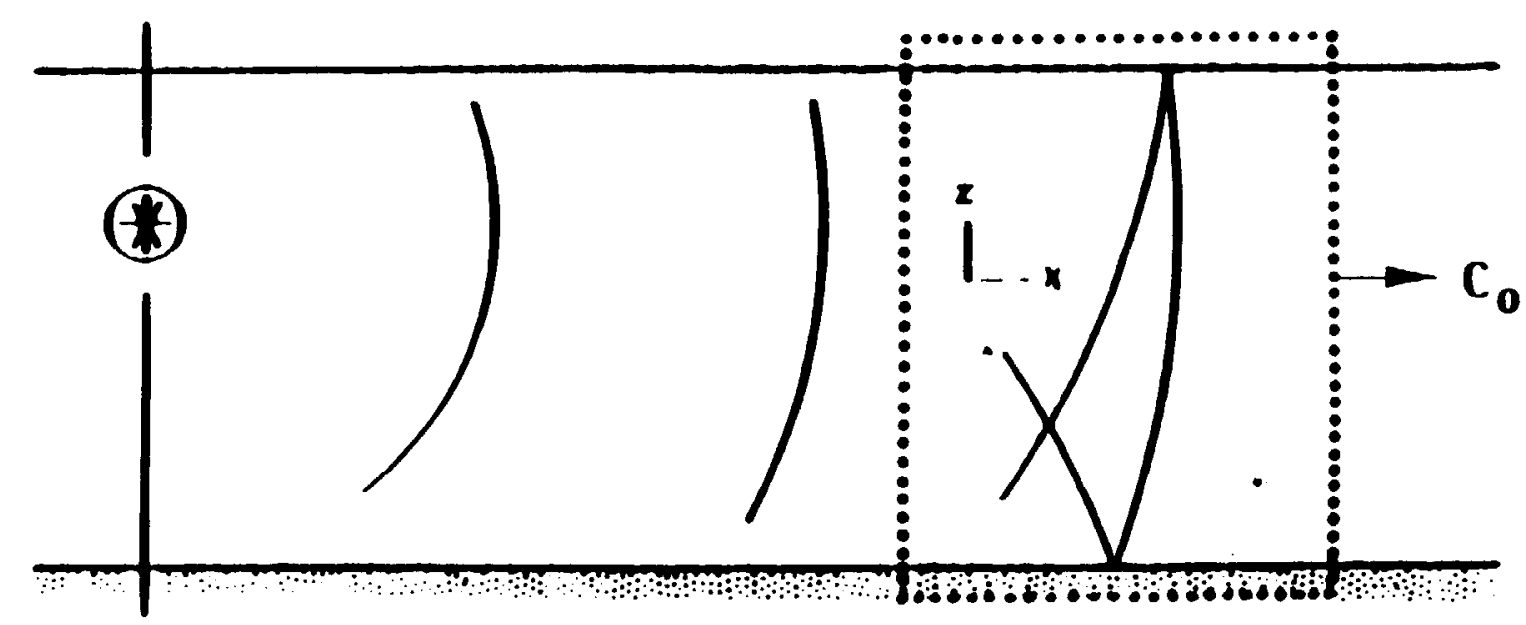

From Ed McDonald, NRL July 1994 


\section{Our model couples the strong shock region (above or below water) to the acoustic regime}

- A sequence of linked codes is required to carry the solution through different physical regimes

- Strong shock to $300 \mathrm{~m}$ : CALE

- Weak shock to $10,000 \mathrm{~m}$ : NPE

- To assess decoupling effects we conducted 10 calculations for sources ranging from:

- A fully-coupled reference event at $1000 \mathrm{~m}$ depth, to

- An explosion $1000 \mathrm{~m}$ above the ocean surface
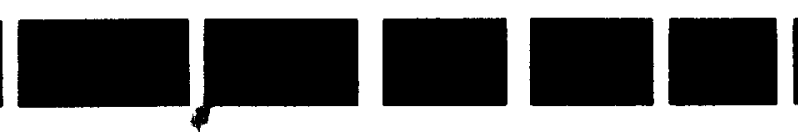

$\sim 300 \mathrm{~m}$

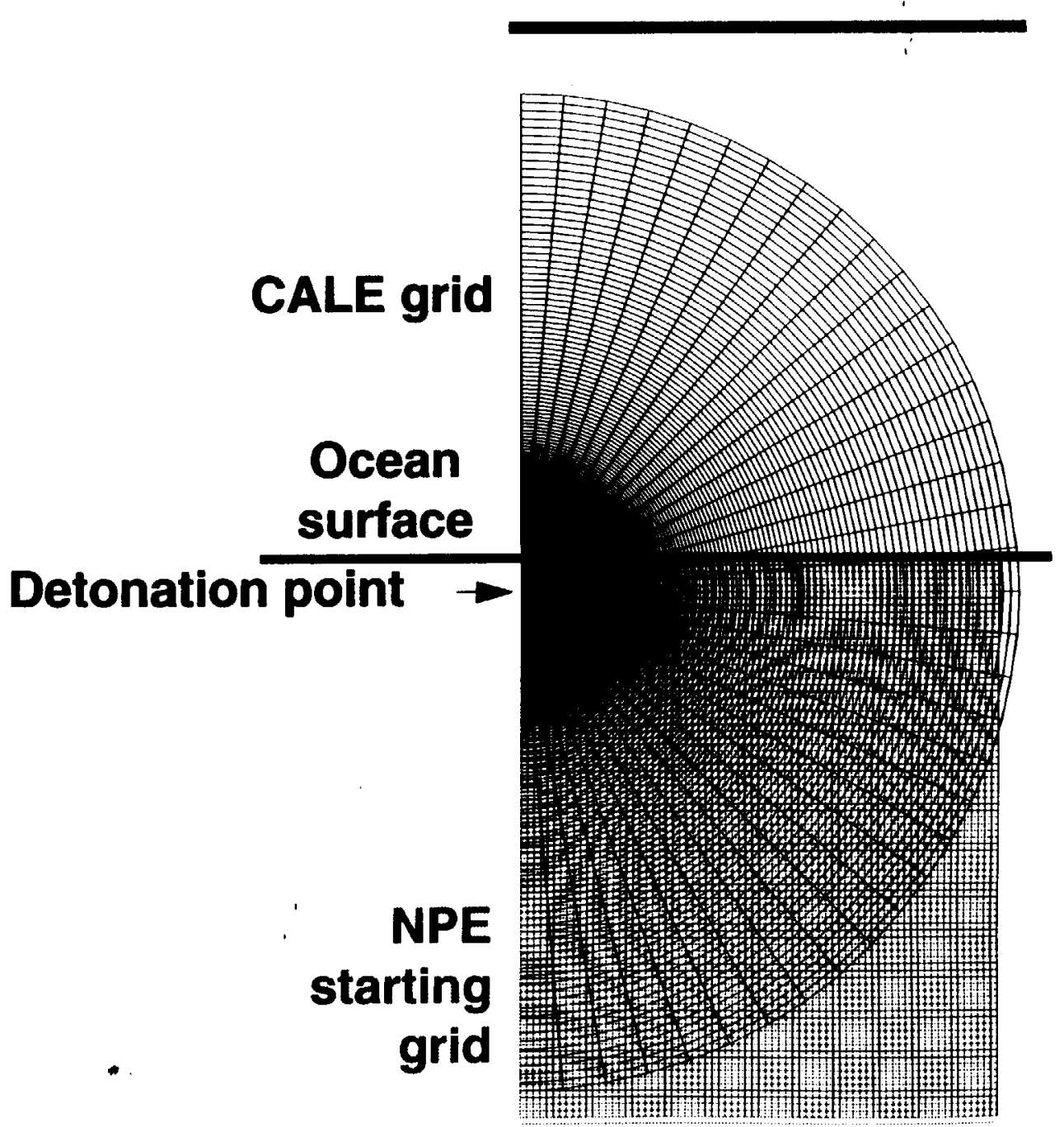




\section{Link process transfers shock wave in water from CALE to NPE}

- Link when wave in water has moved far enough that air blast and device debris can no longer influence wave in an important way

- Link to NPE is made by overlaying motion in water (only) into NPE grid

- Key variable is "overdensity" = water density minus reference density - Set overdensity to zero if density below $1.00 \mathrm{~g} / \mathrm{cc}$

- Result is new input file for NPE 


\section{Example of conditions at link from CALE to NPE}

- Note region of high temperature steam near the axis between the surface and $-40 \mathrm{~m}$ depth.

- Close to the axis the main shock

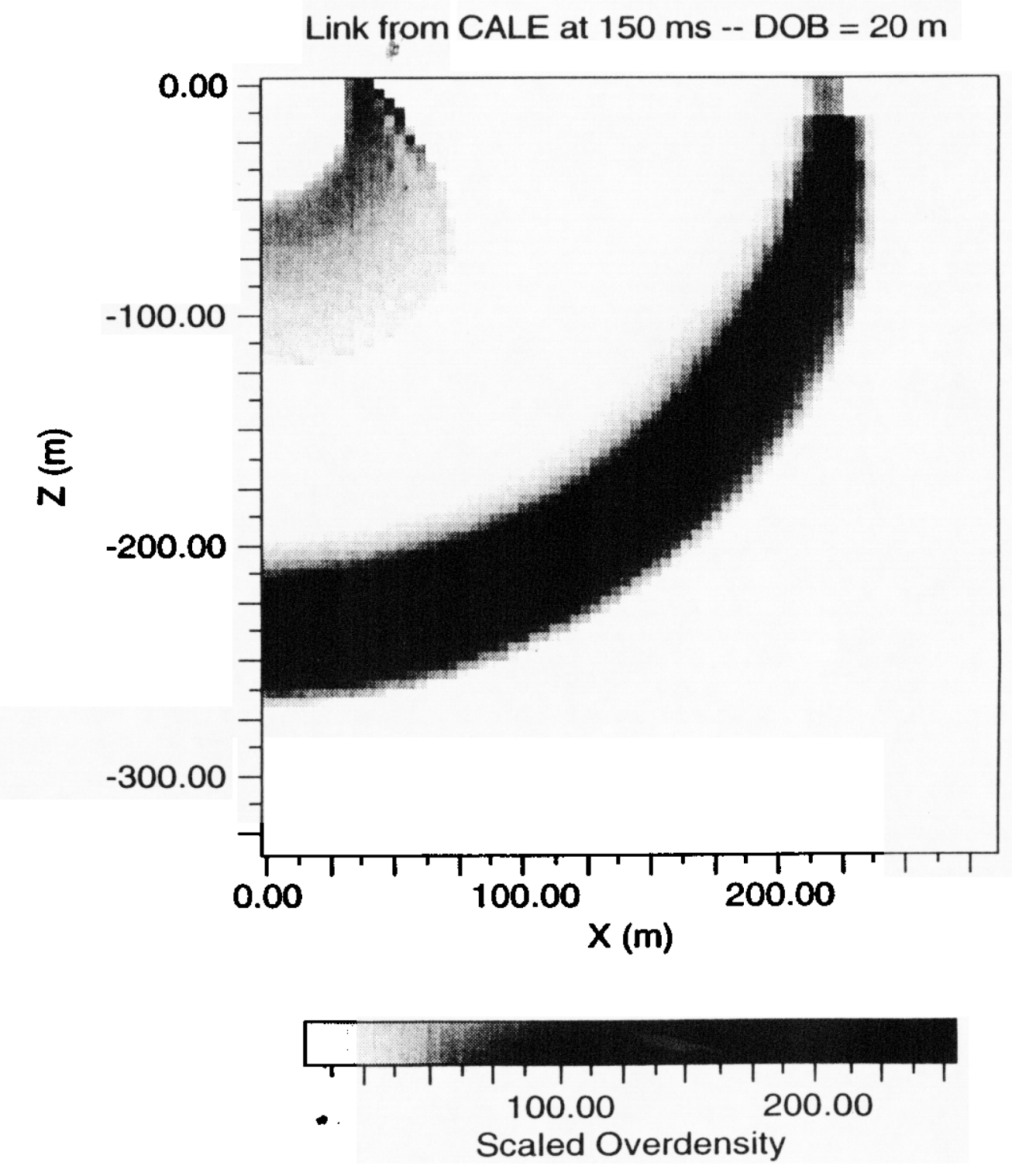

- Peak pressure is about 76 bars $\left(7.6 \times 10^{6} \mathrm{~Pa}\right)$ 


\section{NPE extrapolates the weak shock to the linear regime}

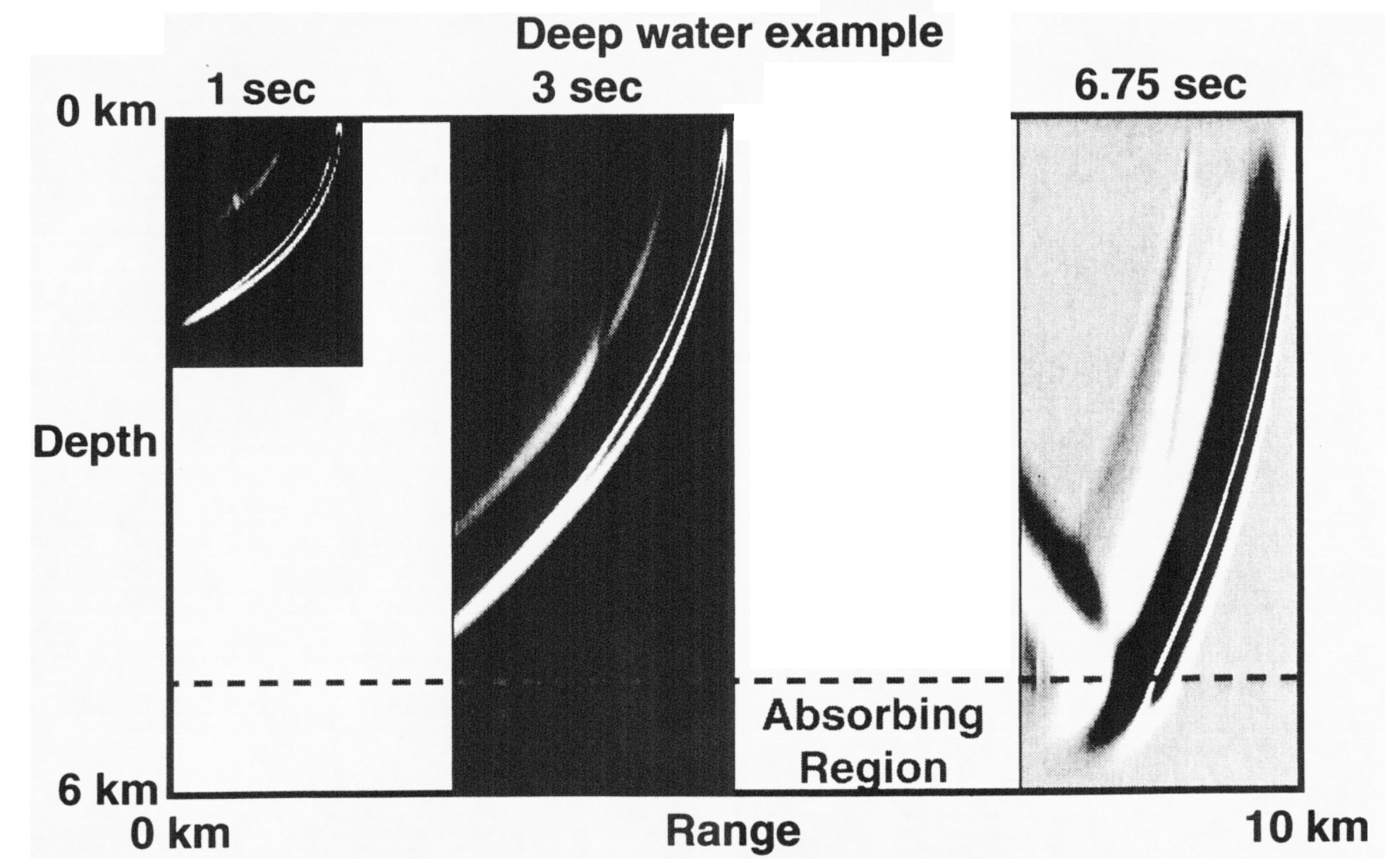

- Uses a travelling grid to track just the initial shock

- Provides a "starter field" at 10 kilometers for linear acoustic models 


\section{NPE grid and main wave at $10,000 \mathrm{~m}$ range}

- Total energy in wave about $0.002 \mathrm{kt}$
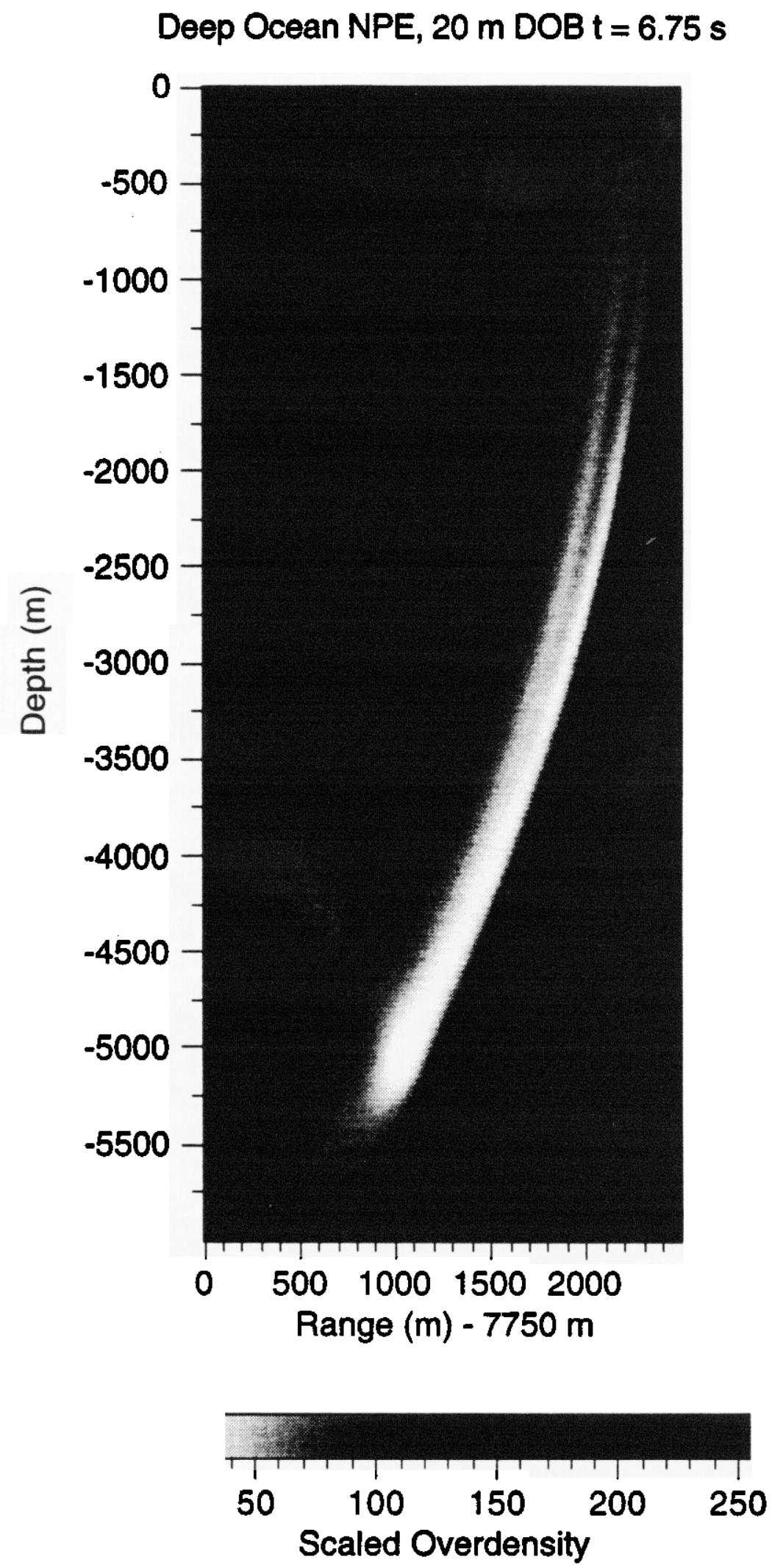


\section{Total wave energy is used to compare NPE results}

- Compare the total energy in the wavefront at about $10 \mathrm{~km}$ range - Time $=6.75$ seconds (except $\mathrm{T}=9 \mathrm{~s}$ for $1 \mathrm{~km} \mathrm{HOB}$ )

- Wavefront total energy is found by summing over the NPE zones - The internal (potential) energy from change in volume (PdV)

- The kinetic energy in each zone

- The total energy in a zone is divided equally into IE and KE and varies as the overdensity squared

Comparison can also be done with:

- Maximum overdensity

- Total linear X momentum

- Analysis of wave frequency content is also useful. 
Coupling efficiency declines precipitously as the burst point is raised through the ocean surface

- CALE/NPE solution for the main shock only, as a function of height or depth of burst

- Peak pressures range from 100,00 $\mathrm{Pa}$ to about $200 \mathrm{~Pa}^{*}$

Total wave energy in NPE at $10 \mathrm{~km}$ range

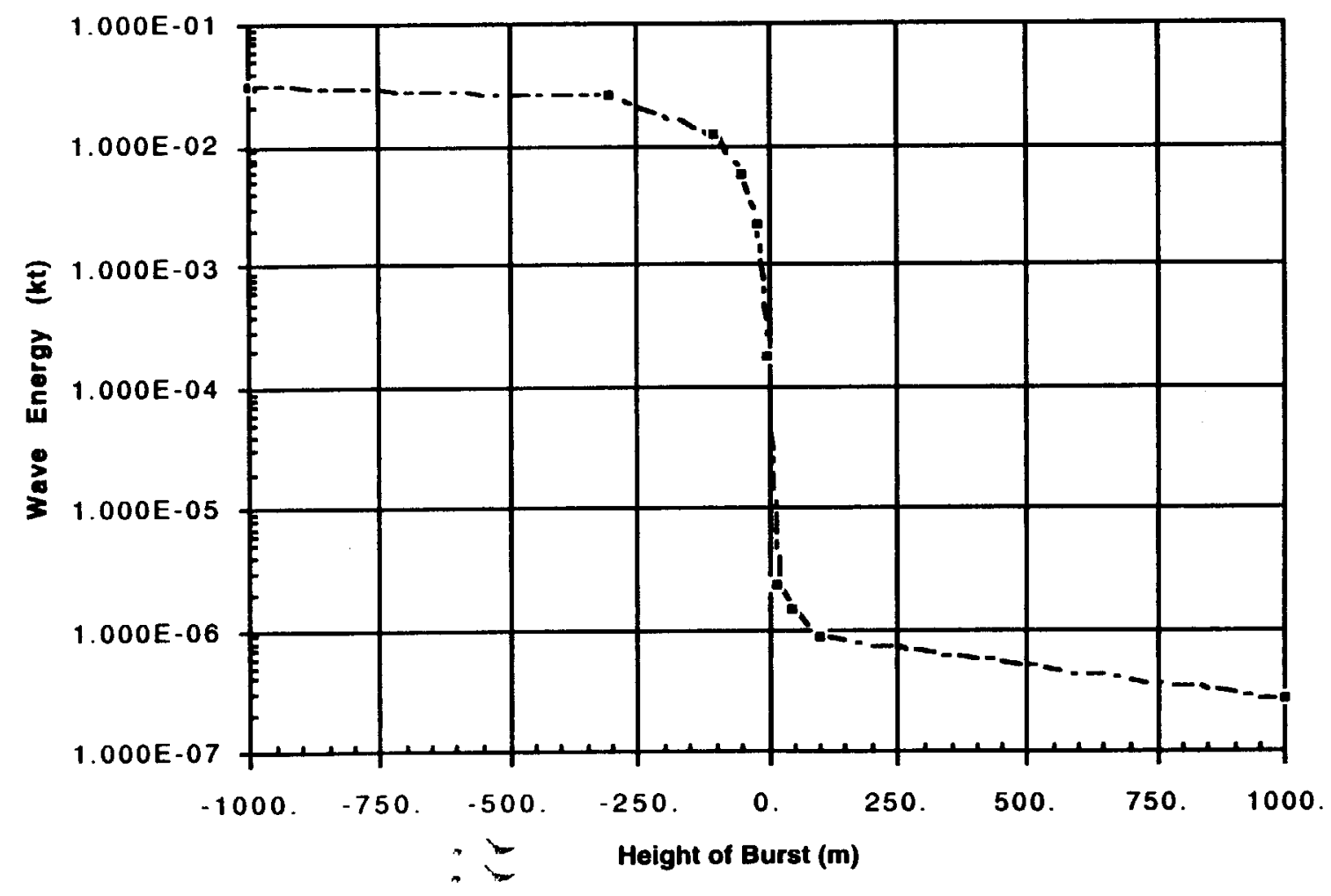

$<-$ Equivalent in energy to 10$50 \mathrm{~kg}$ at SOFAR axis 


\section{Summary of Deep ocean energy coupling study}

- Using the computer codes CALE and NPE, we have completed simulations of ten 1-kiloton explosions

- Depths of burst from $20 \mathrm{~m}$ to $1 \mathrm{~km}$

- Heights of burst from $20 \mathrm{~m}$ to $1 \mathrm{~km}$; plus zero

- Total wave energy at $10 \mathrm{~km}$ range is sharply reduced for burst locations near and above the surface

\section{Signal Characteristics}

- Wave at $10 \mathrm{~km}$ extends from the surface to deep in the ocean

- Most signals have little energy beyond $20 \mathrm{~Hz}$; peak energy is $2-10 \mathrm{~Hz}$

- Burst at $1000 \mathrm{~m}$ depth has energy beyond $100 \mathrm{~Hz}$

- Bursts above the surface have less energy at high frequencies

We expect - Signals will be easily observable, even for burst points well above the surface.

- Procedure in place for transfer to long range acoustic code 
Compare results from three cases

A. Deep Ocean (range independent)

- Typical mid-latitude sound speed profile

$$
\text { Depth }=5000 \mathrm{~m}
$$

,

B. Shallow water, flat bottom

- Somewhat like flat areas of continental shelf.

C. Shallow water sloping to much deeper water

- Crude model of wave propagation from continental shelf into deeper ocean

- All three cases included a soft mud bottom in two layers

- Mud1

- Mud2

$300 \mathrm{~m}$ deep, sound speed $=1670 \mathrm{~m} / \mathrm{s}$ to bottom of grid, sound speed $=2000 \mathrm{~m} / \mathrm{s}$

- Same CALE source: 1 kiloton burst at $50 \mathrm{~m}$ height

- Examine results from NPE to $17 \mathrm{~s}$ (range about $25 \mathrm{~km}$ ) 
- Modified version has coding for mud/silt/sapd layers

- Improved treatment based on work of Ed McDonald

- Bottom is modeled in NPE as a fluid like water

- Higher sound speed than water

- Attenuation approximately $1.0 \mathrm{~dB}$ per wavelength 
- After a brief time in shallow water, the signal propagates down the slope into deeper water

\section{NPE - Sloping Bottom}

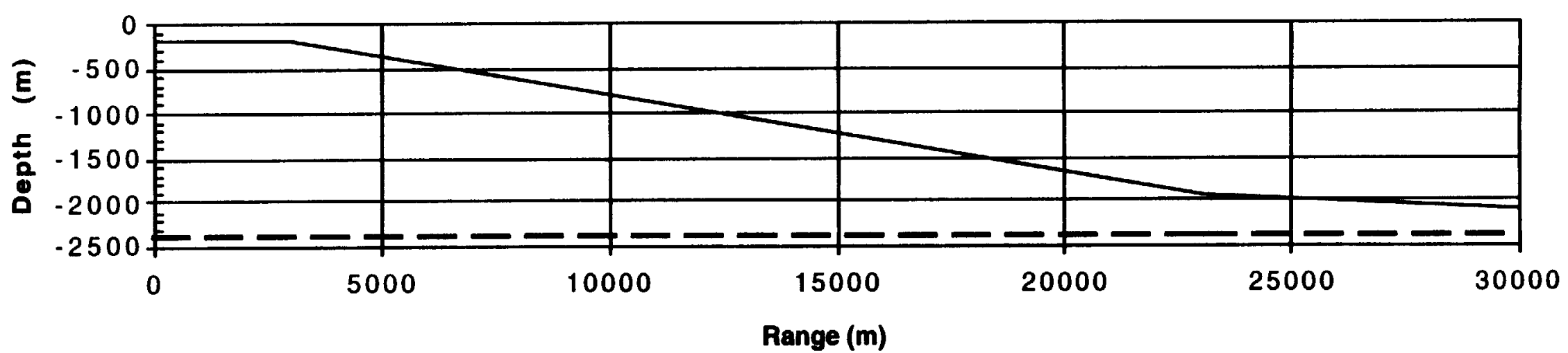

- Vertical Scale in plot enlarged by a factor of two

- Five degree slope approximates slope at continental rise

- Initial water depth $=200 \mathrm{~m}$

- Five degree slope between $3 \mathrm{~km}$ and $23 \mathrm{~km}$ range

- One degree slope beyond $23 \mathrm{~km}$ range

- Maximum water depth in this case about $2200 \mathrm{~m}$ 
$50 \mathrm{~m}$ HOB, sloping bottom $T=17 \mathrm{~s}$
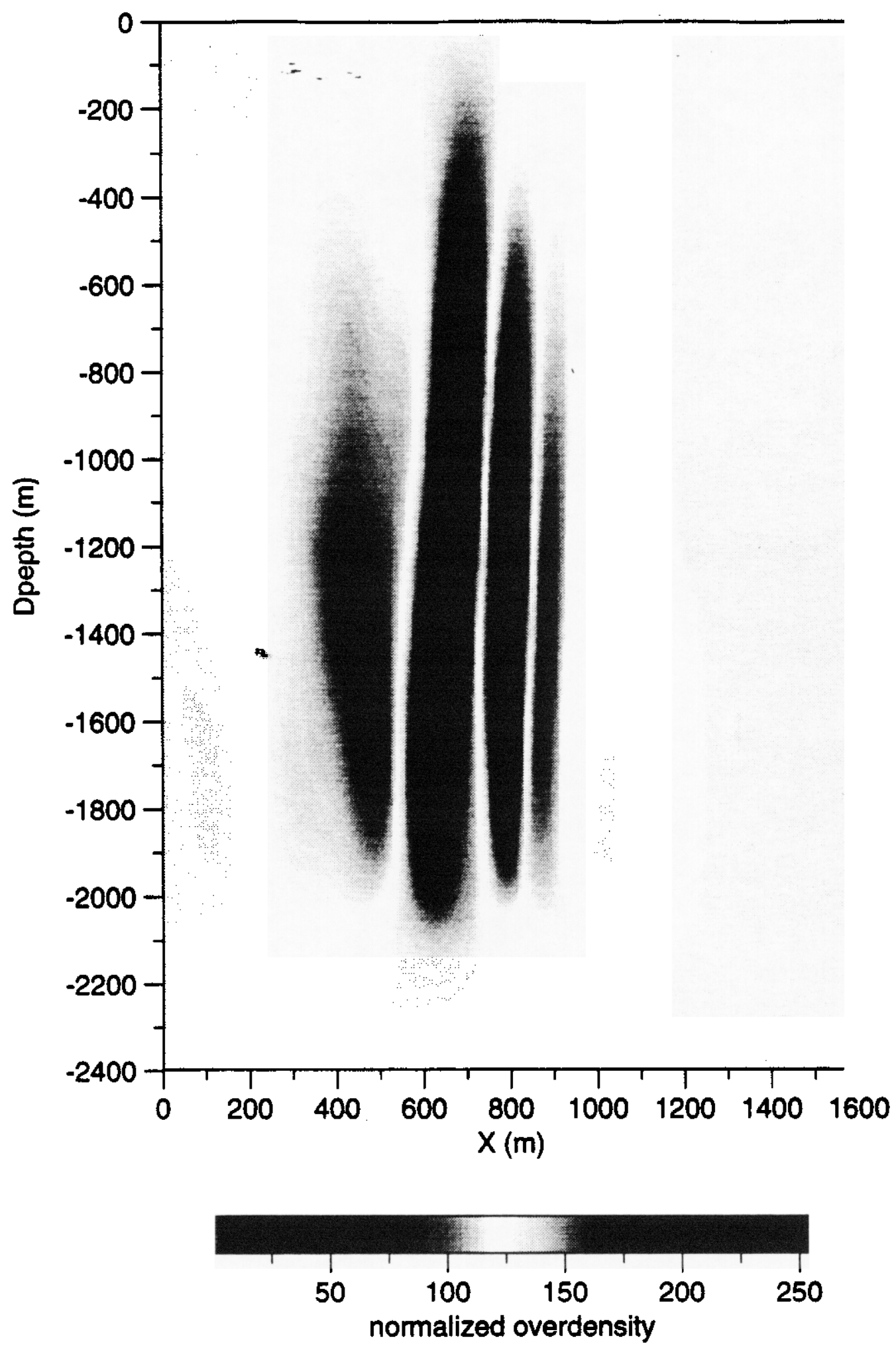
Pictorial results from three calculations of the same burst

- Time = 17 seconds (Range about $25 \mathrm{~km})$

- Deep (5000 m) ocean over mud

Width $3000 \mathrm{~m}=>$

- Shallow water, flat bottom $200 \mathrm{~m}$ deep over mud $1800 \mathrm{~m}$ wide $\times 1600 \mathrm{~m}$ deep $=>$

- Peak pressures 8 -10 times lower than in other two cases.

- Shallow water sloping into deep

- Water depth at $17 \mathrm{~s}$ about $2200 \mathrm{~m}$ $1600 \mathrm{~m}$ wide $\times 2400 \mathrm{~m}$ deep $=>$
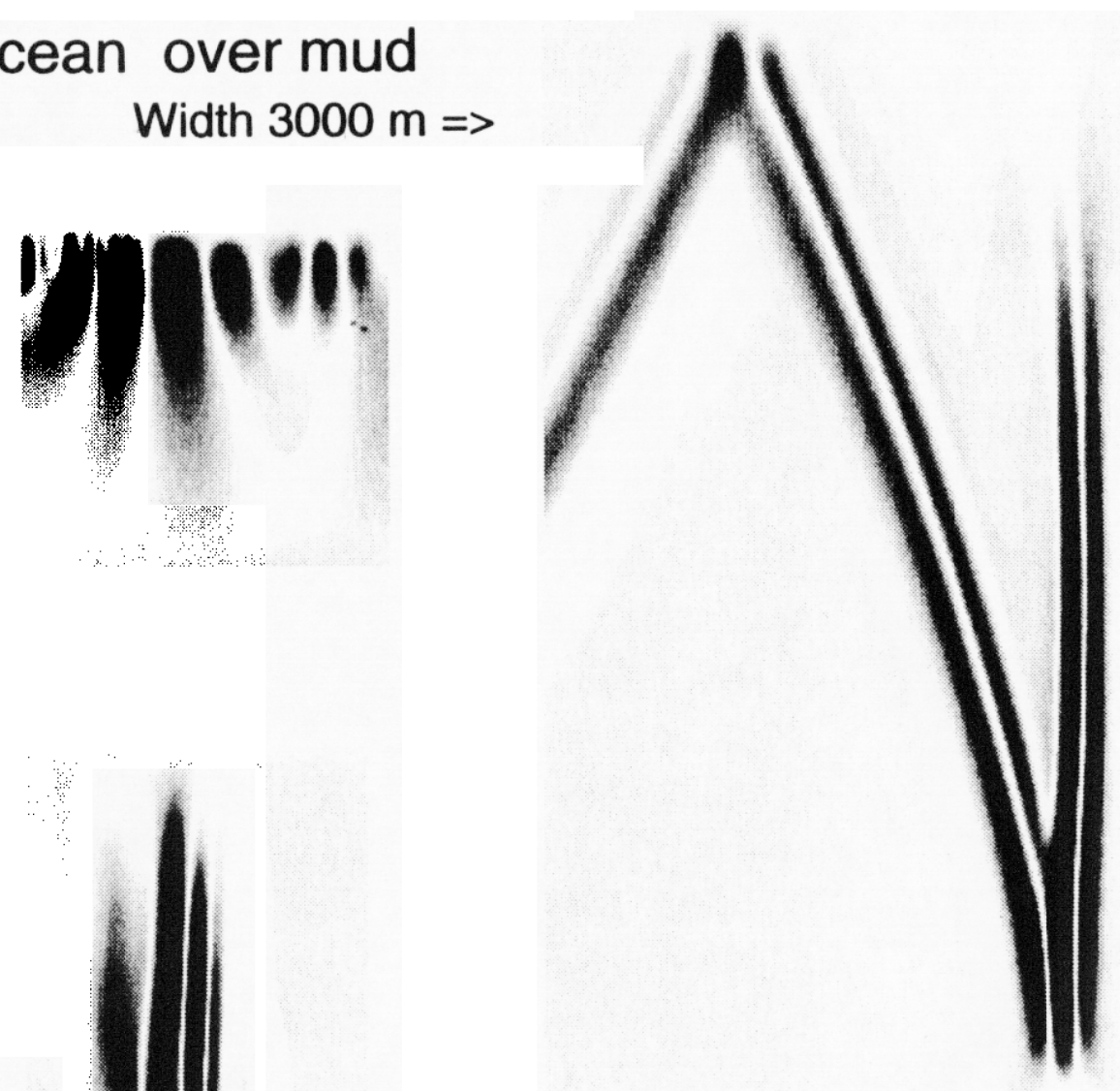
Compare results from three cases

A. $5000 \mathrm{~m}$ Deep Ocean with typical mid-latitude sound speed profile

B. $200 \mathrm{~m}$ deep shallow water, flat bottom

- Somewhat like flat areas of continental shelf

C. Shallow water sloping to much deeper water

- Somewhat like the edge of the continental shelf

- Signal in flat bottom case is 8 - 10 times lower in peak pressure than other two cases

$-25 \mathrm{~km}$ of travel has led to significant loss of energy

- Not much signal energy above $5 \mathrm{~Hz}$

- Shallow water cases have more structure in waves than deep case

Results from this study form a first step in understanding signals in the nearsource region from large explosions in/above a variety of environments

Our goal is to provide a catalog of "starter fields" for long range propagation studies 
Shallow water propagation reduces signal amplitude, disperses the signal and alters it's spectrum
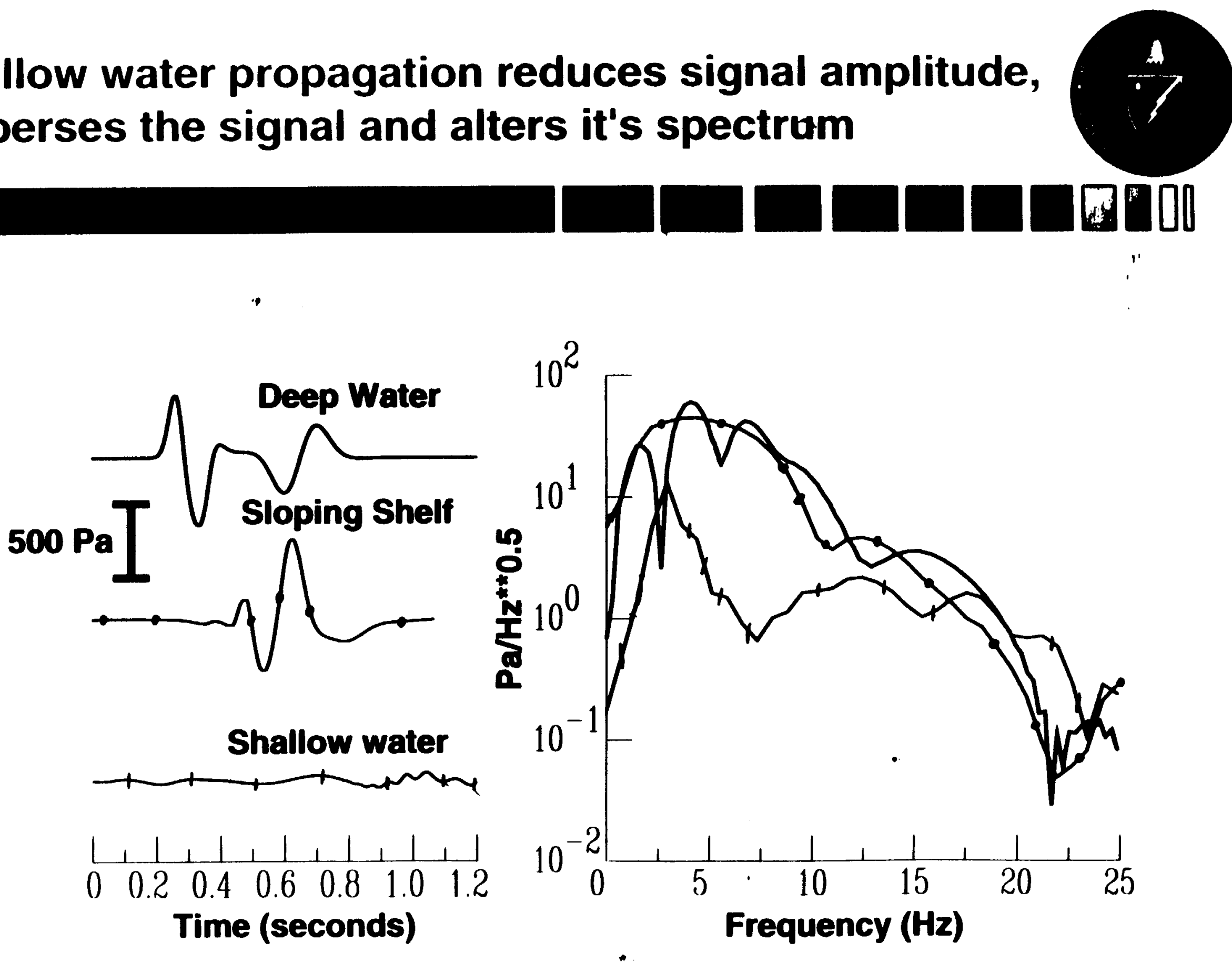
DOE is calculating hydroacoustic source terms for critical monitoring scenarios

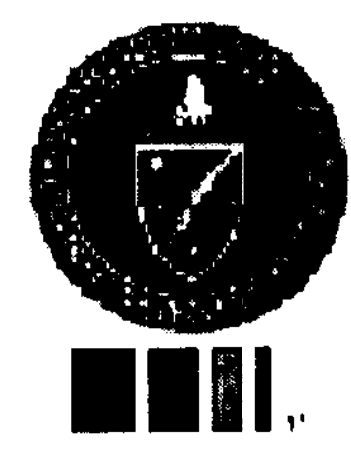

Simulated source-term wave fields for characteristic ocean bottom configurations important for monitoring

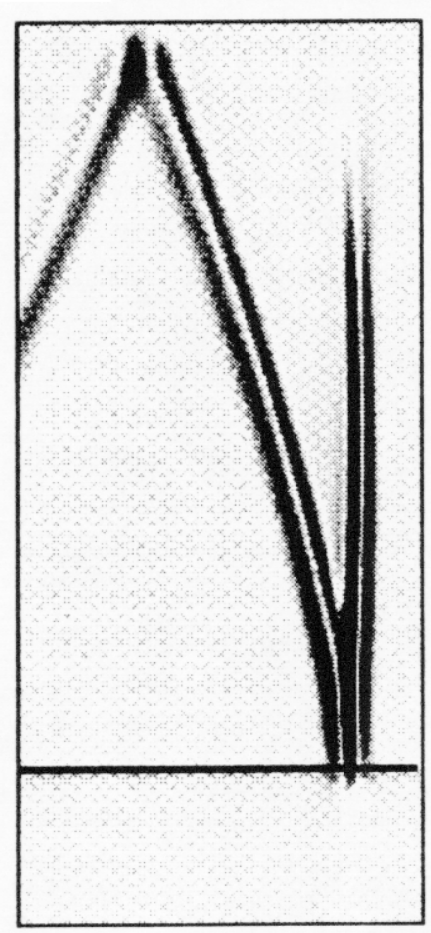

\section{Shallow Water}

Sloping Bottom

Shallow Water

Flat Bottom

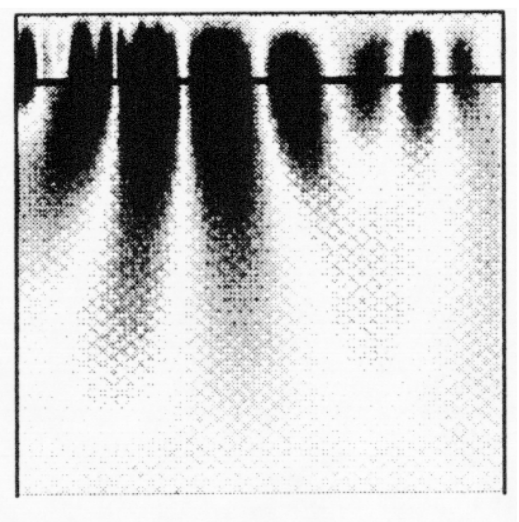

Deep Water Flat Bottom

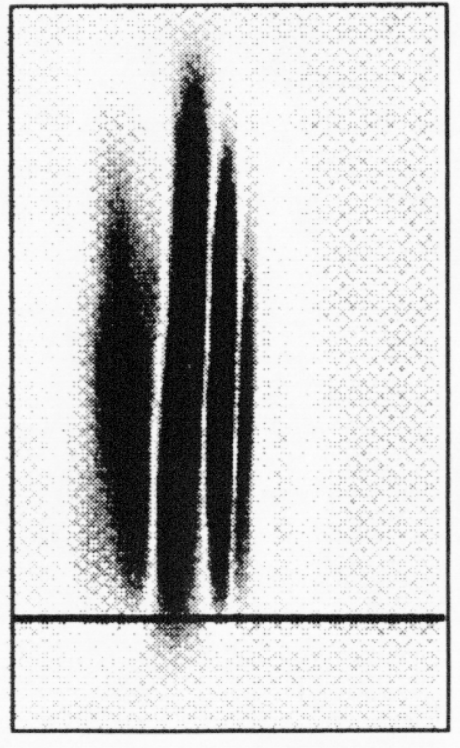

- Ocean bottom configuration has a drastic effect on the pulse leaving the source region

- For the NDC to make accurate event identifications it needs to understand source terms under realistic monitoring conditions 


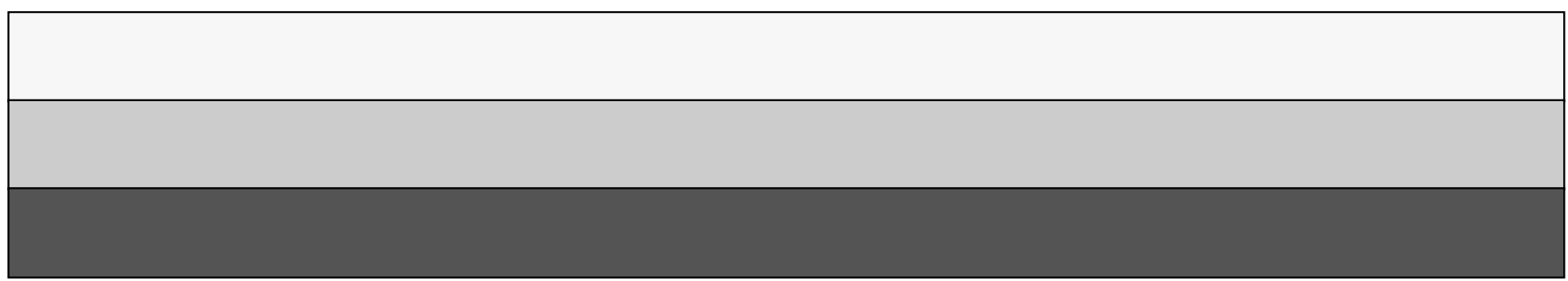

